\title{
Preparation of an Injectable Macroporous $\alpha$-TCP Cement
}

\author{
Andrés Felipe Vásquez Niño ${ }^{a *}$, Luis Alberto Loureiro dos Santos ${ }^{a}$ \\ ${ }^{a}$ Biomaterials Laboratory, Materials Department, Universidade Federal do Rio Grande do Sul- \\ UFRGS, Porto Alegre, RS, Brazil
}

Received: March 17, 2016; Revised: June 21, 2016; Accepted: June 24, 2016

\begin{abstract}
One of the most important characteristics of calcium phosphate cements is their resorbability when implanted in the body. However, the in vivo resorption rate is slow due to the lack of intrinsic open porosity. In this study, macroporous structures were obtained by mixing alpha-tricalcium phosphate $(\alpha-\mathrm{TCP})$ cement with a foamed liquid phase containing different concentrations of sodium hydrogen phosphate and non-ionic (Lutensol) or anionic (Sodium Lauryl Sulfate) surfactant. The cement paste was prepared by hand mixing in a system of two syringes connected by a polyvinyl chloride (PVC) valve, an environmentally friendly method. Solutions with Lutensol (L110) showed greater foamability than solutions with Sodium Lauryl Sulfate (SLS). Scanning Electron Microscopy characterization helped verify that the prepared samples showed a macroporous interconnected structure, and X-ray diffraction analysis evidenced the transformation of $\alpha$-TCP into calcium deficient hydroxyapatite (CDHA). This study suggests that the calcium phosphate cement samples foamed with Lutensol may be further evaluated as suitable materials for bone filling.
\end{abstract}

Keywords: Bioceramics, $\alpha$-TCP, Macroporosity, Bone Cement, Injectable Cement

\section{Introduction}

The bone can be described as a composite material formed by an organic phase and a mineral phase, the latter known as carbonated apatite. Due to the chemical similarity of calcium orthophosphates to the mineral component of bones, they have been widely studied as suitable materials for bone tissue filling and regeneration. Among these ceramics, calcium phosphate cements (CPCs) show remarkable features for such applications, like malleability, injectability, small cavity filling, bioactivity and in situ hardening at room temperature ${ }^{1,2}$. Basically, a viscous paste is formed after mixing a solid phase (cement powder) with a liquid phase (aqueous solution). The paste hardens and the final product of the setting reaction is obtained, calcium deficient hydroxyapatite (CDHA) in the case of apatitic cements, which thanks to its formation at body temperature shows higher chemical and crystallographic similarity to biological apatites and a greater specific surface area than sintered hydroxyapatite ${ }^{3}$. In addition, calcium phosphate cements are resorbable materials, this is, they have the ability to be solubilized and then replaced by new bone tissue ${ }^{4}$.

Even though calcium phosphate cements are microporous and resorbable materials, their resorption rate is too slow. This can be explained by the absence of open porosity with diameters

*e-mail: andres.felipe.vasquez87@gmail.com larger than $100 \mathrm{~mm}$ in bulk material ${ }^{5}$. Resorption of the CPC is done in two ways: The first, called passive resorption, is caused by the interaction of the material with organic fluids and depends on the chemical composition of the hardened cement, on its porosity and crystallinity, and on the $\mathrm{pH}$ of the interphase between the cement surface and the surrounding tissues ${ }^{6,7}$. The second, called active resorption, is caused by the cellular activity of macrophages or osteoclasts, which produce a $\mathrm{pH}$ around 5.5, accelerating the dissolution rate of the cement surface ${ }^{8,9}$. Thus, an interconnected macroporous structure is required to guarantee a higher resorption rate and to guide the formation of new bone through the cement structure (osteoconduction). Cell proliferation is aided by blood vessels formation inside the cement structure, which allows nutrients and oxygen supply, besides protein transport ${ }^{10}$.

Different methodologies have been reported to induce macroporosity in calcium phosphate cements. These procedures are usually the same used to obtain cellular ceramics. Among these techniques replica methods ${ }^{11}$, porogenic agents sacrifice $^{12}$, rapid prototyping ${ }^{13}$ and direct foaming ${ }^{14}$ are predominant. Among the advantages of the latter are the simplicity of the process and the induction of macroporosity before setting, which allows injectability of the foamed paste.

The objective of this work was the evaluation of a new and simple methodology to obtain macroporous calcium phosphate cement. In the 
study, two types of surfactants -Sodium Lauryl Sulfate and Lutensol ON 110- were used for the foaming of an $\alpha$-TCP cement.

\section{Materials and Methods}

The $\alpha$-TCP used in this work was obtained through the wet precipitation method, adding a $0.5 \mathrm{M}\left(\mathrm{NH}_{4}\right)_{2}(\mathrm{HPO})_{4}$ solution (Dinâmica Ltda) into a $0.5 \mathrm{M} \mathrm{Ca}\left(\mathrm{NO}_{3}\right)_{2}$ solution (Sigma Aldrich) previously heated to a temperature of $60^{\circ} \mathrm{C}$ in a round bottom distillation flask with constant stirring of $200 \mathrm{rpm}$. The flow rate of the phosphate solution was fixed at $14 \mathrm{~mL} / \mathrm{min}$. The precipitate was filtered and dried in an oven at $100^{\circ} \mathrm{C}$ for 24 hours. After drying, the material was manually crushed in a porcelain mortar. The powder was then thermally treated in an alumina crucible at $1400^{\circ} \mathrm{C}$ for an hour. Finally, the material was ground again in the mortar and sieved through a \#325 mesh.

Before making the cement samples, the different concentrations of $\mathrm{Na}_{2} \mathrm{HPO}_{4}$ setting accelerant (Synth) and surfactant -Sodium Lauryl Sulfate (Dinâmica Ltda) or Lutensol ON 110 (Basf)- were determined for the liquid phase in order to evaluate its foamability afterwards. For that purpose, a central composite design $2^{2}$ was used, with 4 axial point runs and 3 replicates in central points (11 runs total). The concentrations of $\mathrm{Na}_{2} \mathrm{HPO}_{4}$, SLS and L110 were chosen as independent variables, these are represented in Table 1.

The experimental design for each surfactant was obtained with the Statgraphics Centurion XVI software. Table 2 presents the total number of runs and their experimental combinations.

The response variable, i.e., the foamability of each solution, was determined by collecting $2,2 \mathrm{~mL}\left(V_{i}\right)$ from the solution with different concentrations of of surfactant and $\mathrm{Na}_{2} \mathrm{HPO}_{4}$ (Table 2) with a conventional $10 \mathrm{~mL}$ syringe and then connecting it with a flexible PVC valve to another syringe filled with a fixed air volume (Figure 1a). The solution was injected manually from one syringe to another and a foamed phase was formed because of the turbulence generated in the liquid. The piston push frequency was fixed at 160 bpm $(2.67 \mathrm{~Hz})$ with the help of a digital metronome and the mixing time was 30 seconds.

The foam was injected in a $20 \mathrm{~mL}$ graduated cylinder to measure its volume $\left(V_{f}\right)$. Then, the foamability $(\mathrm{F})$ of each solution is defined by:

$$
F=\left(\frac{V_{f}-V_{i}}{V_{i}}\right) \times 100
$$

After evaluating the solutions for their foamability, six surfactant $/ \mathrm{Na}_{2} \mathrm{HPO}_{4}$ combinations with the greater foam volume formation were chosen to continue the experimental procedure. The cement paste was prepared in two stages: Foaming of the liquid phase, as just described, and mixing of the foam with the cement powder. After foam formation, the foam was kept completely in one of the syringes to subsequently add $3 g$ of $\alpha$-TCP cement to the other syringe. Both phases were then mixed for 15 seconds at $160 \mathrm{bpm}$ (Figure 1b). The cement paste was then injected in cylindrical silicone molds with $8 \mathrm{~mm}$ diameter and $2.7 \mathrm{~mm}$ height. The samples were kept in the molds for 24 hours at $37^{\circ} \mathrm{C}$ and $100 \%$ relative humidity. At last, the samples were removed from the molds and immersed in Ringer's saline solution for $72 \mathrm{~h}$ at $37^{\circ} \mathrm{C}$.

The samples were crushed by a mortar and pestle and the powder was structurally characterized by $\mathrm{X}$-ray diffraction (XRD) in a Phillips X'pert MPD diffractometer over a scan range of $20-40^{\circ}$, with a step size of $0.02^{\circ}$ and a nominal time per step of 2 seconds. Then, the macrostructure of the samples' fracture surface was examined by Scanning Electron Microscopy (SEM) on a JEOL 6060 microscope, after coating them with a thin layer of gold. Pore size distribution was measured for each micrography with the ImageJ software. Finally, porosity was calculated by geometric method. Five samples per solution were evaluated and the average porosity value was calculated.

\section{Results and Discussion}

Figure 2 shows the XRD pattern of the cement powder. This pattern confirms the presence of $\alpha$-TCP

Table 1: Concentrations of independent variables SLS, L110 and $\mathrm{Na}_{2} \mathrm{HPO}_{4}$.

\begin{tabular}{lccccc}
\hline \multirow{2}{*}{ IND. VARIABLES } & \multicolumn{5}{c}{ INDEPENDENT VARIABLE LEVELS (CONCENTRATION) } \\
\hline $\mathrm{SLS}$ & $-\sqrt{2}$ & -1 & 0 & 1 & $\sqrt{2}$ \\
$\mathrm{~L} 110$ & 0.9 & 1.10 & 3.55 & 6.00 & 7.00 \\
$\mathrm{Na}_{2} \mathrm{HPO}_{4}$ & 0.20 & 0.90 & 2.60 & 4.30 & 5.00 \\
\hline
\end{tabular}


Table 2: Experimental combinations of different concentrations of $\mathrm{Na}_{2} \mathrm{HPO}_{4}$ and surfactant.

\begin{tabular}{|c|c|c|c|c|c|}
\hline \multicolumn{3}{|c|}{ Sodium Lauryl Sulfate } & \multicolumn{3}{|c|}{ Lutensol $^{\circledR}$ ON 110} \\
\hline RUN & [ ] SLS (wt\%) & {[]$^{N_{2}} \mathrm{HPO}_{4}(\mathrm{wt} \%)$} & RUN & [ ] L110 (wt \%) & [ ] $\mathrm{Na}_{2} \mathrm{HPO}_{4}(\mathrm{wt} \%)$ \\
\hline S1 & 3.55 & 6.25 & L1 & 2.60 & 6.25 \\
\hline S2 & 1.10 & 3.60 & L2 & 0.90 & 8.90 \\
\hline S3 & 0.09 & 6.25 & L3 & 2.60 & 10.00 \\
\hline S4 & 6.00 & 8.90 & L4 & 0.90 & 3.60 \\
\hline S5 & 7.00 & 6.25 & L5 & 5.00 & 6.25 \\
\hline S6 & 3.55 & 6.25 & L6 & 2.60 & 6.25 \\
\hline S7 & 6.00 & 3.60 & L7 & 4.30 & 8.90 \\
\hline S8 & 1.10 & 8.90 & L8 & 2.60 & 2.50 \\
\hline S9 & 3.55 & 2.50 & L9 & 4.30 & 3.60 \\
\hline S10 & 3.55 & 10.00 & L10 & 0.20 & 6.25 \\
\hline S11 & 3.55 & 6.25 & L11 & 2.60 & 6.25 \\
\hline
\end{tabular}

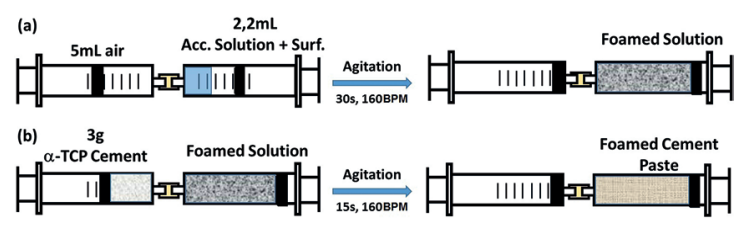

Figure 1: Foaming system, composed by 2 syringes connected by a flexible PVC valve. (a) Foaming of the solution. (b) Obtaining of the foamed cement paste.

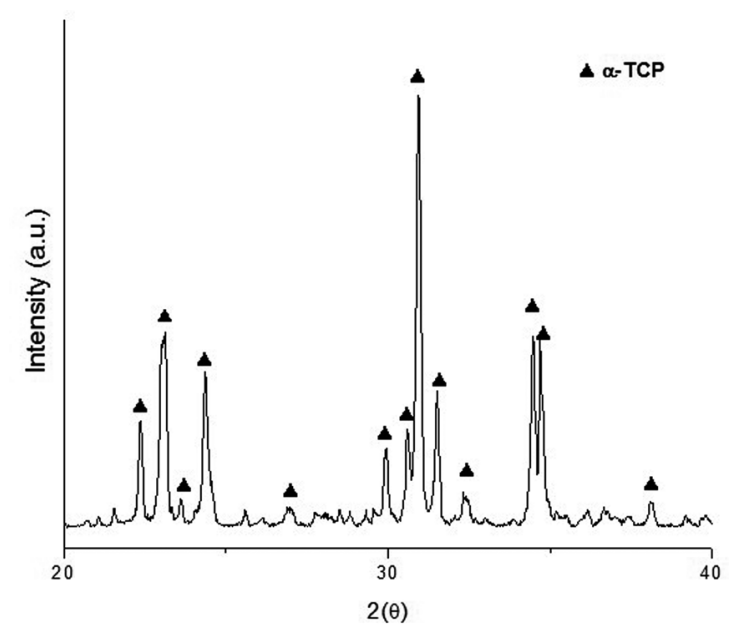

Figure 2: XRD pattern for the powder synthesized through wet precipitation method and charred at $1400^{\circ} \mathrm{C}$ for an hour.

as the only phase in the powder after being thermally treated, when comparing it with the standard file (JCPDS 9-348). There were no peaks corresponding to other calcium phosphate phases like $\beta$-TCP (JCPDS 9-169), HA (JCPDS 9-432) or TTCP (JCPDS 25-1137).

Figure 3 presents the FTIR spectra of the synthesized $\alpha$-TCP powder. Two broad bands at $531-605 \mathrm{~cm}^{-1}$ and $944-1076 \mathrm{~cm}^{-1}$ were observed. The first one corresponds to the anti-symmetric $\mathrm{P}-\mathrm{O}$ bending mode $\left(v_{4}\right)$. Shoulders at 551,566 e $595 \mathrm{~cm}^{-1}$ are superimpose, increasing

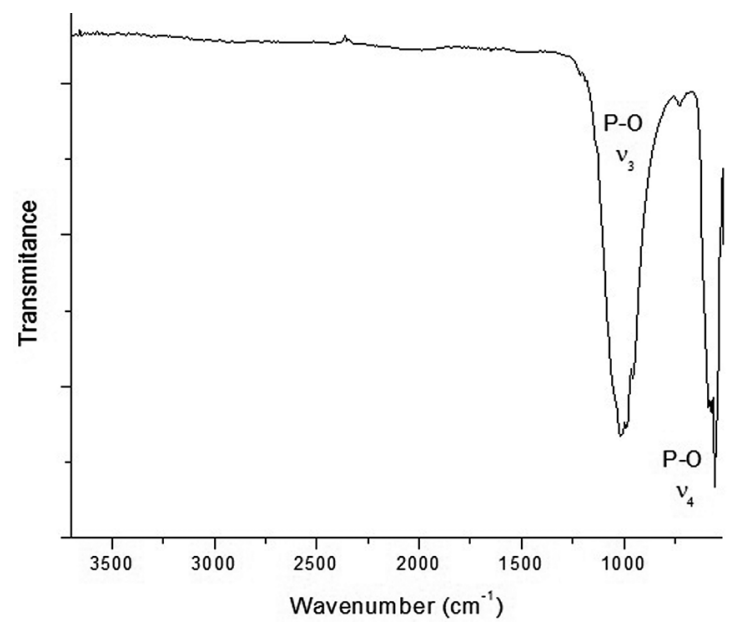

Figure 3. FTIR spectra of the $\alpha$-TCP powder after calcination at $1400^{\circ} \mathrm{C}$.

the wide of the band. The second one, composed by shoulders at 944, 988, 1032 e $1055 \mathrm{~cm}^{-1}$, corresponds to the anti-symmetric $\mathrm{P}-\mathrm{O}$ stretching mode $\left(v_{3}\right)^{15}$. Additionally, bands and shoulders corresponding to $\mathrm{OH}$ groups $\left(630\right.$ and $\left.3570 \mathrm{~cm}^{-1}\right)$ and adsorbed water $\left(3000-3700 \mathrm{~cm}^{-1}\right)$ were not found in the spectra.

Figure 4 shows the response surfaces for foamability as a function of surfactant and sodium phosphate concentrations for the evaluated solutions (Table 2).

As expected, in both cases the surfactant concentration affects significantly $(p<0.05)$ the foamability of the solution. $p$-values calculated for SLS and L110 were 0.0013 and 0.0001 respectively. Furthermore, on both surfaces it is evident that foamability increases with surfactant concentration until it reaches a maximum value and then it diminishes slightly as the surfactant concentration continues to increase. This phenomenon is attributed to the achievement of the critical micelle concentration (CMC) of surfactant in the solution. After reaching this value the foamability will not increase any further and it will tend 

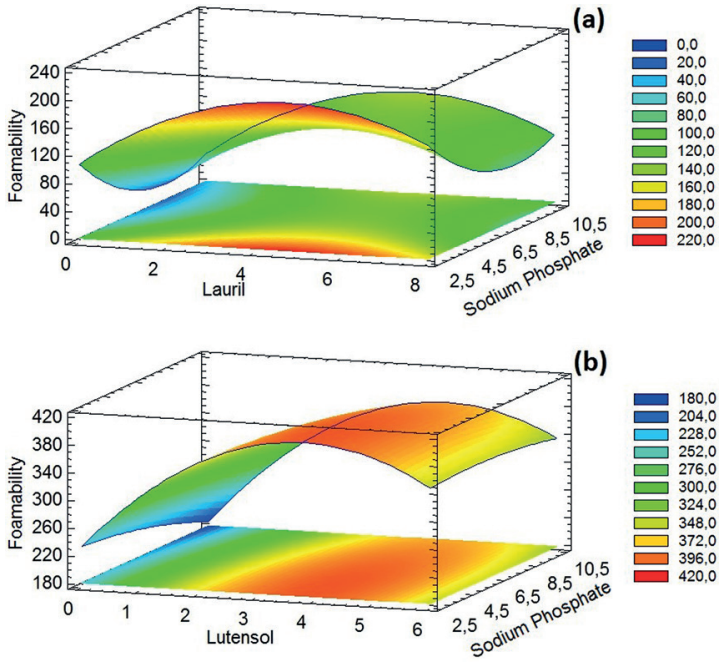

Figure 4: Response surfaces for foamability of solutions with different concentrations of $\mathrm{Na}_{2} \mathrm{HPO}_{4}$ and (a) SLS and (b) L110.

to remain constant ${ }^{16,17}$. $\mathrm{Na}_{2} \mathrm{HPO}_{4}$ concentration was also statistically significant for the foamability of solutions containing SLS ( $p=0.0018)$. Clearly, with the increase of the phosphate salt in the solution its foamability tends to diminish. On the other hand, adding $\mathrm{Na}_{2} \mathrm{HPO}_{4}$ to the solutions containing L110 did not significantly influence their foamability $(p=0.1096)$. This can be explained by the interaction of the electrolyte with the micells of the surfactant. Anionic surfactants (SLS) are more likely than non-ionic (L110) to undergo electrical repulsions between the polar heads of their amphipathic molecules, causing, for example, a reduction of $\mathrm{CMC}^{18}$.

Analyzing and comparing the foamability values of solutions with SLS and L110, it can be concluded that the ones containing Lutensol ON 110 showed a much higher volume increase (\%) after agitation than the ones containing Sodium Lauryl Sulfate; the lowest and highest foamability values corresponded to runs L2 (286.4\%) and L9 (400\%), respectively. The lowest and highest response variable values for SLS solutions were $45.5 \%$ (S3) and $209.1 \%$ (S9), respectively. In other words, the highest foamability value within the SLS runs was lower than the lowest value within the L110 runs. This result confirms the preference of L110 over SLS to continue the present study. The six compositions with higher foamability were chosen, being these L1 (377.3\%); L3 (354.5\%); L5 (390.9\%); L7 (381.8\%); L8 (372.7\%); and L9 (400\%).

Figure 5 shows the XRD pattern for the calcium phosphate cement sample prepared with L5 solution ( $5 \mathrm{wt} \% \mathrm{~L} 110$ and $6.25 \mathrm{wt} \% \mathrm{Na}_{2} \mathrm{HPO}_{4}$ ) after immersion in Ringer's solution for 3 days.

The transformation of $\alpha$-TCP into CDHA after the immersion in Ringer's solution is evident. However, low-intensity peaks corresponding to the precursor

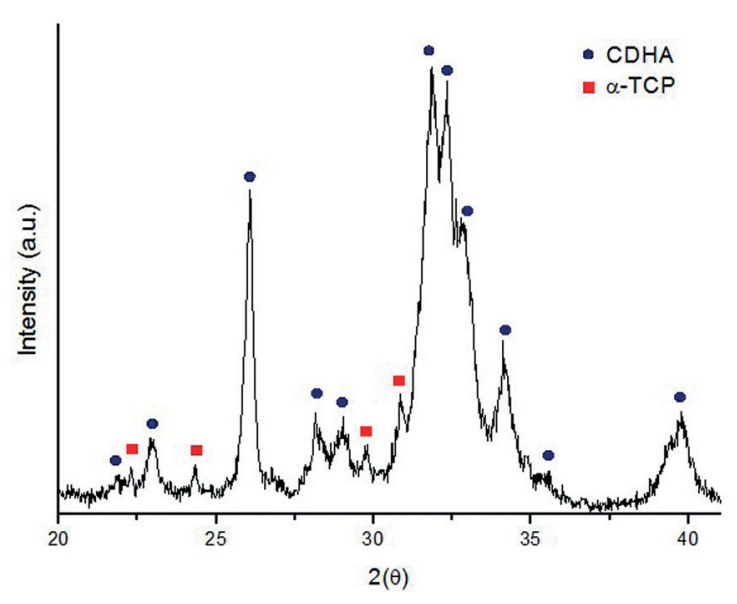

Figure 5: XRD pattern for an $\alpha$-TCP cement sample prepared with L5 solution.

cement powder appear, indicating an incomplete transformation after 3 days. Ginebra et. al. ${ }^{19}$ evaluated the setting reaction of an apatitic cement mixed with a $\mathrm{Na}_{2} \mathrm{HPO}_{4}(2.5 \mathrm{wt} \%)$ liquid phase and reported the complete disappearance of $\alpha$-TCP peaks after a 15 days immersion in Ringer's solution. The cement hardening occurs by the hydration reaction of $\alpha$-TCP in CHDA, according to equation B:

$$
\begin{aligned}
& \alpha-\mathrm{Ca}_{3}\left(\mathrm{PO}_{4}\right)_{2}+\mathrm{H}_{2} \mathrm{O} \rightarrow \mathrm{Ca}_{9}\left(\mathrm{HPO}_{4}\right) \\
& \left(\mathrm{PO}_{4}\right)_{5}(\mathrm{OH}) \quad(\mathrm{B})
\end{aligned}
$$

$\alpha$-TCP hydrolysis is mainly controlled by two mechanisms. In the initial stage, the reaction is limited by the surface area of the cement powder in contact with the liquid, as long as the superficial CDHA layer formed around the initial powder particles allows a fast liquid diffusion through the layer. For this, the CDHA layer must be thin, discontinuous or permeable to ion transport. When the layer covers the particles' surface completely and becomes thicker, the liquid diffusion rate becomes lower than the $\alpha$-TCP salt dissolution rate, meaning the diffusion mechanism controls then the hydrolysis reaction ${ }^{20}$.

Table 3 shows the calculated porosities for the cement samples prepared with the studied solutions. As a reference, the porosity of a control cement sample (C) was calculated, that is, without any surfactant addition to the liquid phase and with a $\mathrm{Na}_{2} \mathrm{HPO}_{4}$ concentration of $2.5 \mathrm{wt} \%$.

The decrease of apparent density as well as the increase of total porosity are evident when comparing the foamed samples to the control cement. Total porosities of the macroporous samples appeared in the range of $80-90 \%$, which was observed in the cross section SEM micrographs, shown in Figure 6.

SEM characterization revealed the samples' highly porous macrostructures with interconnected macropores, 
Table 3: Apparent Density and Total Porosity of foamed CaP cement samples. The standard deviation values are in parentheses.

\begin{tabular}{lcc}
\hline & Apparent Density $\left(\mathrm{g} / \mathrm{cm}^{3}\right)$ & Total Porosity $(\%)$ \\
\hline C & $1,271(0,038)$ & $59,71(1,20)$ \\
L1 & $0,593(0,038)$ & $81,22(1,19)$ \\
L3 & $0,620(0,056)$ & $80,36(1,76)$ \\
L5 & $0,351(0,023)$ & $88,88(0,73)$ \\
L7 & $0,434(0,020)$ & $86,26(0,62)$ \\
L8 & $0,386(0,027)$ & $87,77(0,86)$ \\
L9 & $0,269(0,013)$ & $91,47(0,41)$ \\
\hline
\end{tabular}

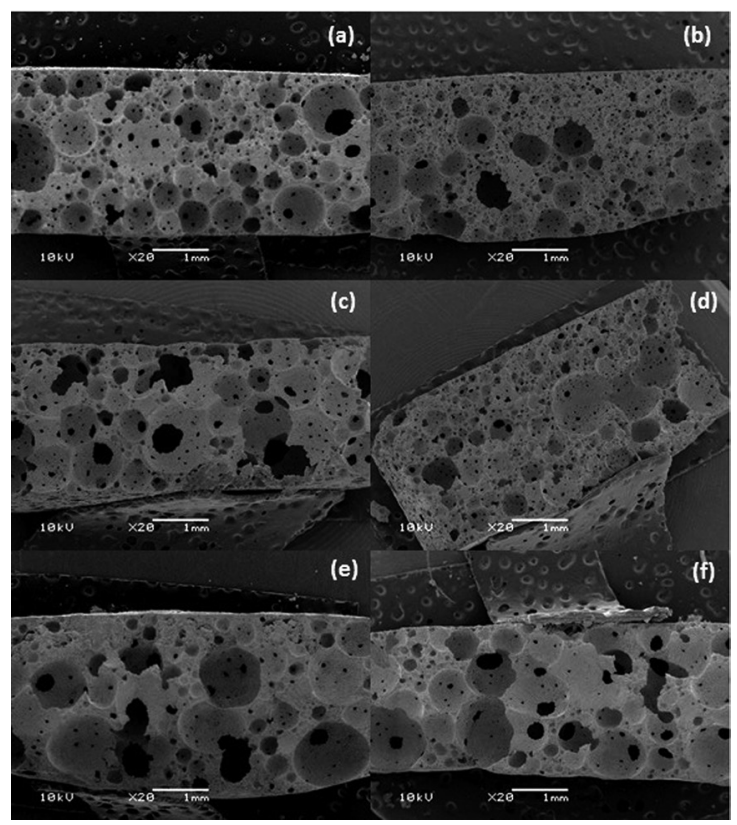

Figure 6: SEM micrographs of the foamed cement samples. (a) L1; (b) L3; (c) L5; (d) L7; (e) L8; (f) L9.

which favors the growth of new bone tissue through the structure of the material and allows the permeation of body fluids like blood and nutrients ${ }^{10}$. The samples with lowest apparent density and highest porosity were the ones prepared with solutions L5 (Figure 5c) and L9 (Figure 5f), which had the highest surfactant proportions: 5 and $4.30 \mathrm{wt} \%$, respectively. The sample with lowest porosity, according to the values in Table 3, was the one prepared with L3 solution. This was confirmed by Figure 5b, which evidences the presence of minor macropores in the structure. Even though the cement prepared with L3 has the same L110 proportion (2.6wt\%) as the cements prepared with $\mathrm{L} 1$ and $\mathrm{L} 8$, the $\mathrm{Na}_{2} \mathrm{HPO}_{4}$ proportion is different, being $10 \mathrm{wt} \%$ for $\mathrm{L} 3$ and 6.25 and $2.50 \mathrm{wt} \%$ for $\mathrm{L} 1$ and $\mathrm{L} 8$, respectively. In other words, the Disodium Hydrogen Phosphate concentration also influences the cements' final macrostructure. Figure 7 shows the pore size distribution for the cement samples.

Although the L3 sample shows some macropores with diameters larger than $200 \mathrm{~mm}$, most of the pores

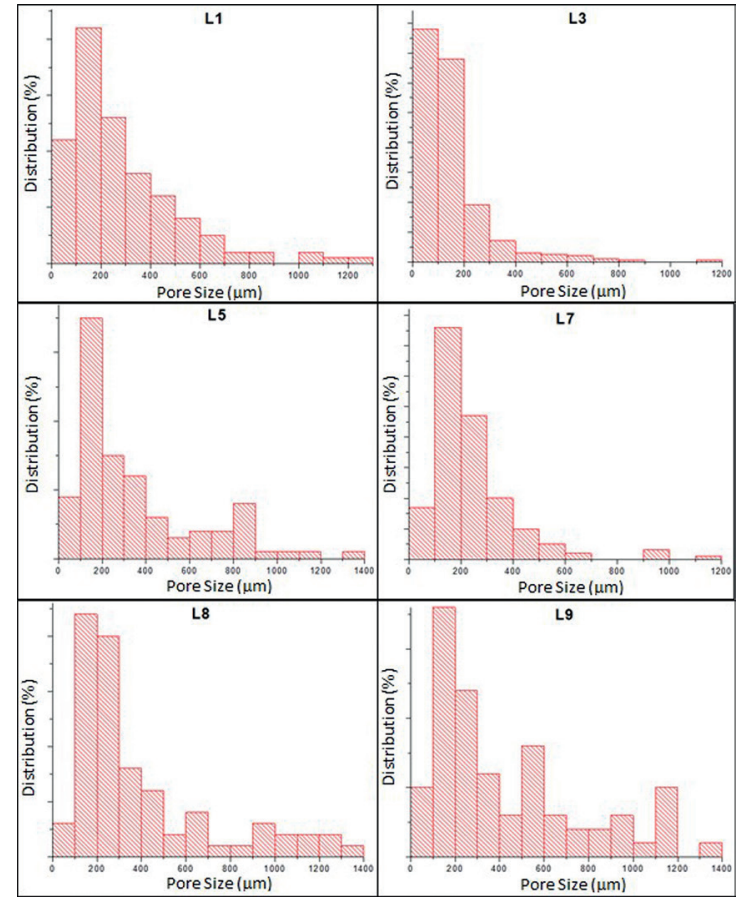

Figure 7: Pore size distribution of the cement samples.

are within the $10-100 \mathrm{~mm}$ range, meaning that besides having the lowest total porosity, it also has the lowest pore size distribution among all the tested specimens. This is a consequence of the high $\mathrm{Na}_{2} \mathrm{HPO}_{4}$ proportion, which accelerates the setting reaction, avoiding bubble coalescence in the foamed cement. Foam is an unstable thermodynamic system because of its large interfacial area, which increases considerably the system's free energy. Therefore, after forming the foam, physical phenomena take place leading to a free energy reduction and so destabilizing the foam ${ }^{16}$. This is known as foam maturation. One of the phenomena involved in the maturation process is the gas diffusion from smaller to bigger bubbles. As a result, smaller bubbles tend to disappear while bigger bubbles increase their size ${ }^{16}$. A lower setting time means greater opposition to the air diffusion process and consequently to bubble growth. This is why the samples with lower $\mathrm{Na}_{2} \mathrm{HPO}_{4}$ proportion show a greater population with pore sizes over $200 \mathrm{~mm}$.

The minimum pore size required for the use of cement as a scaffold in tissue engineering is $100 \mathrm{~mm}$. Seeing this, all the cement samples prepared here may be considered as candidates for further evaluation as suitable materials for bone substitutes. Therefore, the results obtained in this study support the use of the proposed mixing method to fabricate macroporous cement samples. At the beginning of the experimentation, no evidence was found in the literature of related methods to prepare foamed calcium phosphate cement samples. However, early this year, the work of Zhang et al. ${ }^{21}$ was 
published, where a similar method to obtain calcium phosphate cement scaffolds was suggested.

\section{Conclusions}

$\alpha$-TCP macroporous cement samples were prepared by manually mixing the cement powder with the foamed liquid phase using a syringe method, a new approach to obtain macroporous calcium phosphate cements. The foamability analysis revealed that solutions with different Lutensol ON 110 concentrations formed a greater foam volume than solutions with Sodium Lauryl Sulfate. Because of this, the cement samples were prepared with L110 foam and they showed open macropores with pore sizes greater than $100 \mathrm{~mm}$. The macrostructure of the cement samples was influenced both by the surfactant and the $\mathrm{Na}_{2} \mathrm{HPO}_{4}$ concentrations in the liquid phase. Obtained samples have potential to be further evaluated as suitable materials for bone filling and regeneration in non-load-bearing areas.

\section{References}

1. del Real RP, Ooms E, Wolke JG, Vallet-Regí M, Jansen JA. In vivo bone response to porous calcium phosphate cement. Journal of Biomedical Materials Research. Part A. 2003;65(1):30-36.

2. dos Santos LA, Carrodéguas RG, Rogero SO, Higa OZ, Boschi AO, de Arruda ACF. Alpha-tricalcium phosphate cement: “in vitro" cytotoxicity. Biomaterials. 2002;23(9):2035-2042.

3. Almirall A, Larrecq G, Delgado JA, Martínez S, Planell JA, Ginebra MP. Fabrication of low temperature macroporous hydroxyapatite scaffolds by foaming and hydrolysis of an $\alpha$-TCP paste. Biomaterials. 2004;25(17):3671-3680.

4. Constantz BR, Barr BM, Ison IC, Fulmer MT, Baker J, McKinney L, et al. Histological, chemical, and crystallographic analysis of four calcium phosphate cements in different rabbit osseous sites. Journal of Biomedical Materials Research. 1998;43(4):451-461.

5. Burg KJL, Porter S, Kellam JF. Biomaterial developments for bone tissue engineering. Biomaterials. 2000;21(23):2347-2359.

6. LeGeros RZ, Parsons JR, Dalculsi G, Driessens F, Lee D, Liu ST, et al. Significance of the porosity and physical chemistry of calcium phosphate ceramics. Biodegradation - bioresorption. Annals of the New York Academy of Sciences. 1988;523:268-271.
7. Unosson J, Montufar EB, Engqvist H, Ginebra MP, Persson C. Brushite foams-the effect of Tween ${ }^{\circledR} 80$ and Pluronic ${ }^{\circledR}$ F-127 on foam porosity and mechanical properties. Journal of Biomedical Materials Research. Part B, Applied Biomaterials. 2016;104(1):67-77.

8. Shimazaki K, Mooney V. Comparative study of porous hydroxyapatite and tricalcium phosphate as bone substitute. Journal of Orthopaedic Research. 1985;3(3):301-310.

9. Dorozhkin SV. Self-Setting Calcium Orthophosphate Formulations. Journal of Functional Biomaterials. 2013;4(4):209-311.

10. Shepherd JH, Best SM. Calcium phosphate scaffolds for bone repair. JOM The Journal of The Minerals, Metals \& Materials Society (TMS). 2011;63(4):83-92.

11. Miao X, Hu Y, Liu J, Wong AP. Porous calcium phosphate ceramics prepared by coating polyurethane foams with calcium phosphate cements. Materials Letters. 2004;58(3-4):397-402.

12. Xu HHK, Weir MD, Burguera EF, Fraser AM. Injectable and macroporous calcium phosphate cement scaffold. Biomaterials. 2006;27(24):4279-4287.

13. Akkineni AR, Luo Y, Schumacher M, Nies B, Lode A, Gelinsky M. 3D plotting of growth factor loaded calcium phosphate cement scaffolds. Acta Biomaterialia. 2015;27:264-274.

14. Montufar EB, Traykova T, Gil C, Harr I, Almirall A, Aguirre A, et al. Foamed surfactant solution as a template for self-setting injectable hydroxyapatite scaffolds for bone regeneration. Acta Biomaterialia. 2010;6(3):876-885.

15. Carrodeguas RG, De Aza S. $\alpha$-Tricalcium phosphate: Synthesis, properties and biomedical applications. Acta Biomaterialia. 2011;7(10):3536-3546.

16. Schramm LL. Emulsions, Foams, and Suspensions: Fundamentals and Applications. Weinheim: Wiley - VCH Verlag; 2005.

17. Porter MR. Handbook of Surfactants. New York: Springer Science; 1993.

18. Holmberg K, ed. Handbook of Applied Surface and Colloid Chemistry. Volume 2. New Jersey: Wiley; 2002.

19. Ginebra MP, Fernández E, De Maeyer EA, Verbeeck RM, Boltong MG, Ginebra J, et al. Setting reaction and hardening of an apatitic calcium phosphate cement. Journal of Dental Research. 1997;76(4):905-912.

20. Ginebra MP, Fernández E, Driessens FCM, Planell JA. Modeling of the Hydrolysis of $\alpha$-Tricalcium Phosphate. Journal of the American Ceramic Society. 1999;82(10):2808-2812.

21. Zhang J, Liu W, Gauthier O, Sourice S, Pilet P, Rethore G, et al. A simple and effective approach to prepare injectable macroporous calcium phosphate cement for bone repair: Syringefoaming using a viscous hydrophilic polymeric solution. Acta Biomaterialia. 2016;31:326-338. 